Article

\title{
Integrated Amorphous Silicon p-i-n Temperature Sensor for CMOS Photonics
}

\author{
Sandro Rao *, Giovanni Pangallo and Francesco Giuseppe Della Corte \\ Received: 8 November 2015; Accepted: 25 December 2015; Published: 6 January 2016 \\ Academic Editor: Vittorio M.N. Passaro \\ Department of Information Engineering Infrastructures and Sustainable Energy (DIIES), “Mediterranea" \\ University, Reggio Calabria 89122, Italy; giovanni.pangallo@unirc.it (G.P.); \\ francesco.dellacorte@unirc.it (F.G.D.C.) \\ * Correspondence: sandro.rao@unirc.it; Tel.: +39-0965-169-3274
}

\begin{abstract}
Hydrogenated amorphous silicon (a-Si:H) shows interesting optoelectronic and technological properties that make it suitable for the fabrication of passive and active micro-photonic devices, compatible moreover with standard microelectronic devices on a microchip. A temperature sensor based on a hydrogenated amorphous silicon $\mathrm{p}-\mathrm{i}-\mathrm{n}$ diode integrated in an optical waveguide for silicon photonics applications is presented here. The linear dependence of the voltage drop across the forward-biased diode on temperature, in a range from $30^{\circ} \mathrm{C}$ up to $170{ }^{\circ} \mathrm{C}$, has been used for thermal sensing. A high sensitivity of $11.9 \mathrm{mV} /{ }^{\circ} \mathrm{C}$ in the bias current range of $34-40 \mathrm{nA}$ has been measured. The proposed device is particularly suitable for the continuous temperature monitoring of CMOS-compatible photonic integrated circuits, where the behavior of the on-chip active and passive devices are strongly dependent on their operating temperature.
\end{abstract}

Keywords: p-i-n diode; temperature sensors; amorphous silicon; photonic integrated circuit

\section{Introduction}

Si-based photonic devices have experienced tremendous progress in recent years [1-3] and a large scale fabrication of photonic and combined photonic-electronic integrated circuits (PEICs) show a strong uptrend in developing markets like datacom, telecommunication, and sensing [4-9].

Hydrogenated amorphous silicon $(\mathrm{a}-\mathrm{Si}: \mathrm{H})$ is, in particular, a promising platform enabling the desired matching between electronics and on-chip photonics [10]. In a back-end approach, thin layers of a-Si:H can be in fact deposited on top of electronic microchips using the CMOS-compatible low-temperature plasma-enhanced chemical vapor deposition (LT-PECVD) technique, with no impact at all on the underlaying microelectronic circuit. a-Si:H can be also deposited on different substrates where crystalline silicon (c-Si) could not, be it a glass, a metal, an already processed silicon ( $\mathrm{Si}$ ) wafer, or even plastic.

However, many fabricated microelectronic or photonic integrated devices are very sensitive to external variations including temperature, bias voltage, and working wavelengths. In particular, Si-photonic active devices are strongly temperature-dependent, namely they are sensible to the environment temperature modifications due to the large thermo-optic (TO) coefficient of Si [11]. In the last decades, the refractive index temperature dependence has been modeled analytically and the Si TO coefficient has been related to the variation of the inter-band transition energies at some critical points of the Si band structure [12]. Moreover, it has been shown that the TO coefficient of a-Si:H is slightly higher than that of c-Si, resulting, respectively, $d n / d T=2.3 \times 10^{-4} \mathrm{~K}^{-1}$ [13] and $d n / d T=1.8 \times 10^{-4} \mathrm{~K}^{-1}[12]$ at the wavelength of $1550 \mathrm{~nm}$ at $\mathrm{T}=300 \mathrm{~K}$, which might diminish in part the advantages brought by the easy and low cost technology of a-Si:H. 
As anticipated, in fact, refractive index variation with temperature can determine a non-correct behavior of integrated active devices such as interferometers, modulators, photodiodes, sensors. Therefore, thermal challenges need to be resolved in order to advance the silicon photonics to its final industrial stage. For example, the thermal sensitivity of the resonant wavelength for Si-based ring resonators is, e.g., approximately $100 \mathrm{pm} /{ }^{\circ} \mathrm{C}[14]$ or, to mention another example, in a Mach Zehnder (MZ) interferometer the TO effect is responsible of a wavelength shift of $90 \mathrm{pm} /{ }^{\circ} \mathrm{C}[15]$. In Vernier effect-based photonic sensors, the microchip must be thermally stabilized to prevent the drift of the sensor output signal [16]. Consequently, the temperature-dependent optical performance of an on-chip integrated photonic device is a real issue to be taken into account during the design of PEICs [17], and these devices are not practical without a continuous thermal compensation during their operating life.

Recently, on-chip temperature measurement has been proposed for thermal variation compensation in many sensing devices such as humidity, pressure, flow, stress and gas concentration sensors [18].

Among different types of integrated temperature-sensing devices, the advantage of diode-based temperature sensors is the compatibility with IC technology, the low manufacturing costs, the quasi-linear output voltage-temperature, $V_{D^{-}} T$, behavior while preserving a high sensitivity [19].

When a diode operates as a temperature sensor, it is forward-biased at a current $I_{D}$ kept constant over the whole temperature working range and the corresponding voltage drop $V_{D}$ allows an accurate indirect temperature measurement. Low values of bias currents reduce device self-heating and the negative effects of the parasitic series resistance among which are a poorer linearity and sensitivity [20].

In the last years, few examples of a-Si:H p-i-n diode have been proposed as temperature sensor in a temperature range from $\mathrm{T}=30^{\circ} \mathrm{C}$ up to $90^{\circ} \mathrm{C}$. The devices showed a good linearity and a sensitivity of $3.2 \mathrm{mV} /{ }^{\circ} \mathrm{C}$ for a DC bias current of $10 \mathrm{nA}$ [21].

In this work, a temperature sensor based on an a-Si:H p-i-n diode integrated in photonic layer is presented in detail. The sensor is placed very close to a MZ electro-optic modulator in order to monitor the chip temperature variations. The linear dependence of the voltage drop across the forward-biased diode on temperature from $T=30^{\circ} \mathrm{C}$ up to $170{ }^{\circ} \mathrm{C}$ has been accurately measured.

\section{Device Structure}

The diode temperature sensor was integrated in the proximity to a Mach Zehnder interferometer (MZI), Figure 1a,b, and in particular close to the MZI arm where the propagating optical signal is phase shifted by carrier depletion induced in turn by the electric-field applied across the p-i-n diode. The schematic layout of the realized device is shown in Figure 1c together with its geometrical dimensions. More details about the MZI fabrication and operation are provided in [22,23].

The schematic cross section of the fabricated a-Si:H waveguide, integrating the vertical p-i-n diode is shown Figure 1d. It consists of an intrinsic a-Si:H layer, 2- $\mu \mathrm{m}$-thick, between a p-doped a-SiC:H, 2- $\mu$ m-thick, and an n-doped a-SiC:H, 300-nm-thick. The p-i-n cathode top contact is a 200-nm-thick Al layer. The active area of the device is $2.25 \times 10^{-4} \mathrm{~cm}^{2}$.

As well-known, the $I_{D}$ current flowing in a p-i-n diode at a given applied voltage $V_{D}$ can be analytically described using the following formula:

$$
I_{D}=I_{S}\left(e^{\frac{q V_{D}}{\eta k T}}-1\right)
$$

where $\eta$ is the ideality factor, $I_{s}$ is the saturation current, $q$ is the electric charge and $k$ is the Boltzmann constant.

The characterization of the sensor output has been performed under forward bias condition where, at constant DC current, the voltage across the diode is linearly dependent on the temperature. 
In fact, for $\left.q \cdot V_{D}>\right\rangle \cdot k \cdot T$, the voltage dependence on temperature can be obtained from Equation (1), yielding:

$$
V_{D}=\frac{k T}{q} \eta \ln \left(\frac{I_{D}}{I_{S}}\right)
$$

Equation (2) makes explicit the linear dependence $V_{D}-T$ as long as the non-linear contribution of $I_{S}$ can be considered negligible with respect to $I_{D}[24,25]$.

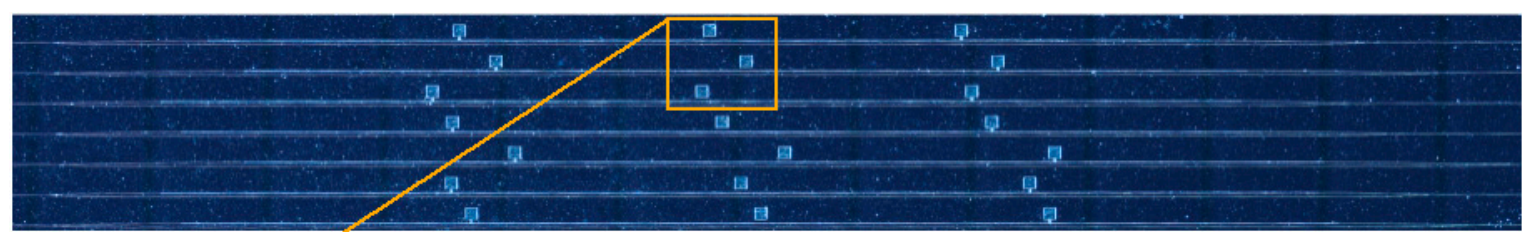

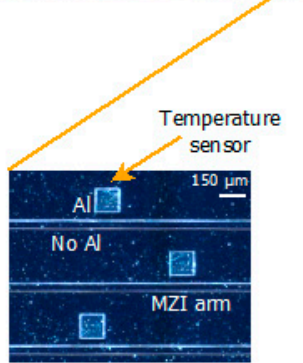

(b)

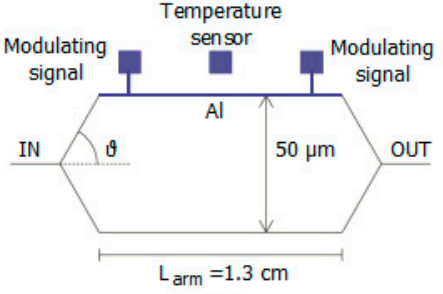

(c)

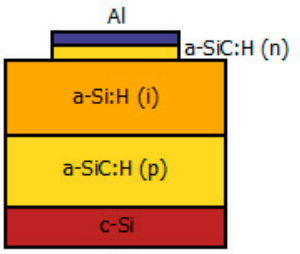

(d)

Figure 1. (a) An optical microscope image (top view) of the a-Si:H-based MZI modulators and temperature sensors; (b) temperature sensor detail; (c) schematic MZI and temperature sensor (plot not in scale); and (d) cross section of the integrated a-Si:H p-i-n diode temperature sensor.

\section{Experimental Results and Discussion}

In our setup, the $\mathrm{p}-\mathrm{i}-\mathrm{n}$ diodes were biased with a current $I_{D}$ kept constant in the whole temperature range. The devices were tested in a climatic chamber (Galli Genviro-030-C) setting the reference temperature through its internal PID digital microcontroller. A calibrated PT100 sensor, with an accuracy of $\pm 0.3^{\circ} \mathrm{C}$, was placed in contact with the device under test in order to monitor, during the measurements, the exact temperature set points gradually varied from (to) $30^{\circ} \mathrm{C}$ to (from) $170{ }^{\circ} \mathrm{C}$. By using an Agilent 4155C semiconductor parameter analyzer, tests were made for $I_{D}$ varied in a range from $1 \mathrm{nA}$ to $80 \mathrm{nA}( \pm 100 \mathrm{pA}$ accuracy and $10 \mathrm{pA}$ resolution, for generated currents in the range $-100 \mathrm{nA}<I_{D}<100 \mathrm{nA}$ ) and the corresponding voltage drop $V_{D}$ across the a-Si:H p-i-n diode was measured. In Figure 2a we report the $I_{D}-V_{D}$ characteristics, for different temperatures in a range from $30{ }^{\circ} \mathrm{C}$ up to $170{ }^{\circ} \mathrm{C}$.

From $I_{D^{-}} V_{D^{-}}$T measurements, a highly linear behavior of the voltage drop across the p-i-n diode on different temperatures was extracted, as shown in Figure $2 \mathrm{~b}$.

In our analysis, the coefficient of determination $\left(R^{2}\right)$ [26] has been calculated to evaluate the agreement between the experimental measurements and their linear best-fit, $f_{L}(T)$. In particular, $R^{2}$ allowed us to quantify the sensor linearity goodness by fitting the experimental data with a linear model.

In the same figure, the measured data are fitted with the best-calculated linear model showing a good degree of linearity $\left(R^{2}>0.995\right)$ for the whole considered range of $I_{D}, 3.7 \mathrm{nA}$ to $80 \mathrm{nA}$.

The sensor sensitivity, $S$, is defined as the temperature derivative of Equation (2) and, therefore, it can be calculated from the slope of the $V_{D^{-}} T$ characteristics.

As reported in Figure $2 \mathrm{~b}$, when $I_{D}$ is $3.7 \mathrm{nA}$ the sensitivity is $10.39 \mathrm{mV} /{ }^{\circ} \mathrm{C}$ and increases up to $12.15 \mathrm{mV} /{ }^{\circ} \mathrm{C}$ for $I_{D}=80 \mathrm{nA}$. 


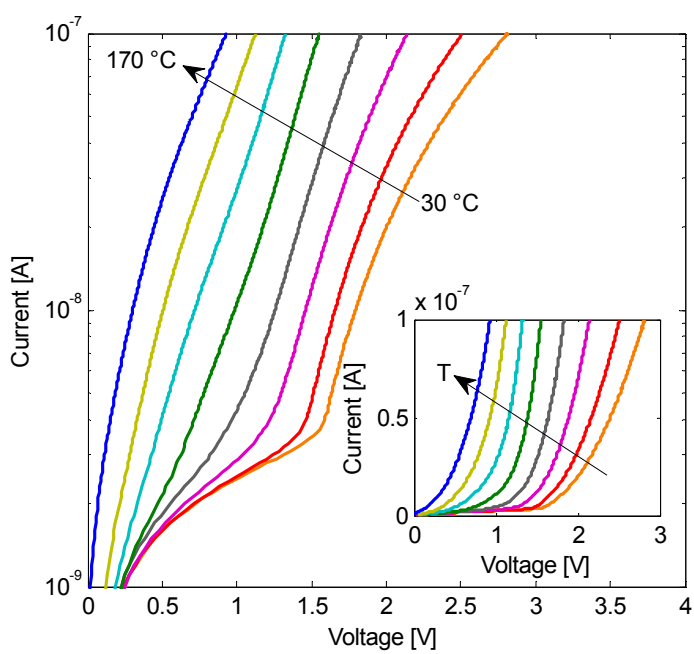

(a)

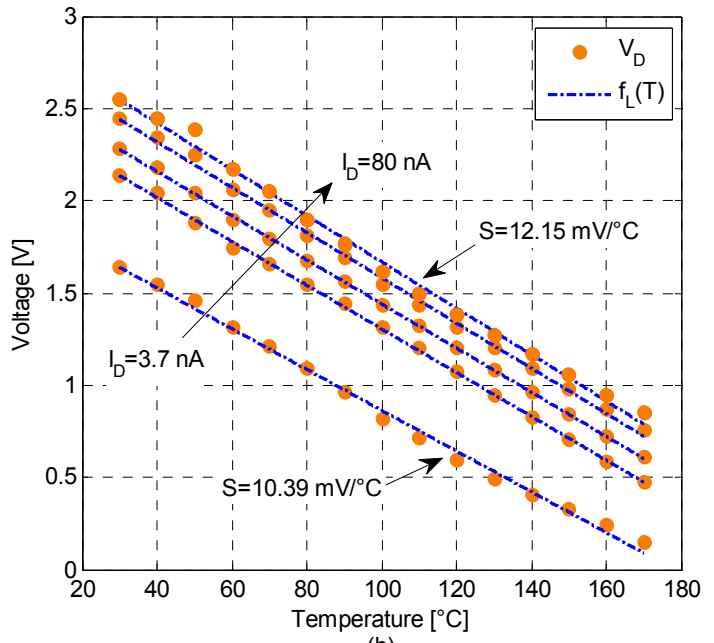

(b)

Figure 2. (a) Forward current-voltage characteristics for temperatures ranging from $30{ }^{\circ} \mathrm{C}$ up to $170{ }^{\circ} \mathrm{C}$, with $\Delta T=20^{\circ} \mathrm{C}$ steps. The inset shows a detail of the $I_{D}-V_{D}$ characteristics in linear scale. (b) Measured (points) forward voltages versus temperature at different bias currents $\left(I_{D}=3.7,22.8,37.3,60.4,80 \mathrm{nA}\right)$. Experimental data are fitted with the best-calculated linear model $f_{L}(T)$.

A more detailed analysis of $R^{2}$ and $S$ is shown in Figure 3a,b for all values of $I_{D}$ in steps of $100 \mathrm{pA}$. It is worth noting that the coefficient of determination varies by only $0.25 \%$ from an average of $R_{a}{ }^{2}=0.9972$ over the considered temperature range leading to a temperature sensor with a highly linear behavior in a wide range of biasing currents. The maximum of $R^{2}=0.9996$ occurs in the current range $\approx 34-40 \mathrm{nA}$. Within this current range, the sensitivity is constant, $S=11.93 \mathrm{mV} /{ }^{\circ} \mathrm{C}$.

To evaluate the mismatch between the calculated linear best-fit, $f_{L}(T)$, and the experimental measurements, the corresponding root mean square error ( $r m s e$ ) was first calculated and subsequently converted into a temperature error value using the following formula:

$$
\operatorname{rmse}\left[{ }^{\circ} \mathrm{C}\right]=\frac{\sqrt{\frac{\sum_{i=1}^{n}\left(V_{D}\left(T_{i}\right)-f_{L}\left(T_{i}\right)\right)^{2}}{n}}}{S}
$$

where $n$ is the number of the temperature set points.

The calculated plot, rmse versus $I_{D}$, for the considered temperature range is reported in Figure 3c. The temperature error is always lower than $3.5^{\circ} \mathrm{C}$, while the minimum rmse $=0.89 \pm 0.01{ }^{\circ} \mathrm{C}$ is obtained for $I_{D}=37.3 \pm 3.3 \mathrm{nA}$.

It is worth noting that the current source accuracy of $\pm 100 \mathrm{pA}$ falls within the above reported range of $I_{D}$ for which the rmse and the sensitivity remain almost constant with no impact on the sensor performances. In practical applications, if we consider that the proposed device is intended for integration on a VLSI electronic microchip, the well-known technics for current stabilization based on bandgap references and current mirrors circuits could be used in association [27].

The temperature resolution, $\varepsilon_{T}$, of a sensor measuring a temperature $T$ is limited by the measurement system resolution, $\varepsilon_{V}$, according to the expression:

$$
\varepsilon_{T}=\frac{\varepsilon_{V}}{S}
$$

when the sensitivity of the sensor, $S=d V / d T$, does not change significantly within the considered temperature range. In our experimental setup, the measured voltage resolution is $20 \mu \mathrm{V}$ leading to a theoretical device resolution of $1.7 \mathrm{~m}^{\circ} \mathrm{C}$. 
The large sensitivity allows in principle the resolution of small temperature variations, however, the smallest detectable temperature change is limited by several error sources including sensor and measurement system calibration, bias current and measured voltage accuracy, noise, sensor self-heating, etc.

The specific applications our integrated a-Si:H sensor is intended for, require however temperature measurements with an accuracy of the order of $\pm 1^{\circ} \mathrm{C}$ about.

In fact, if we consider, e.g., the wavelength division multiplexing (WDM) technique for fiber-optic communications, in which multiple optical signal channels are carried by a single fiber at different wavelengths of light, the spacing between two adjacent wavelengths is not smaller than $\Delta \lambda \sim 1 \mathrm{~nm}$. In particular, for coarse wavelength division multiplexing (CWDM) is about $\Delta \lambda=10-20 \mathrm{~nm}$, while in dense wavelength division multiplexing (DWDM) the spacing is about 0.8 to $2 \mathrm{~nm}$ [28]. Due to the tight spacing, DWDM systems require elaborate temperature control systems to ensure that the optical channels do not interfere each other.

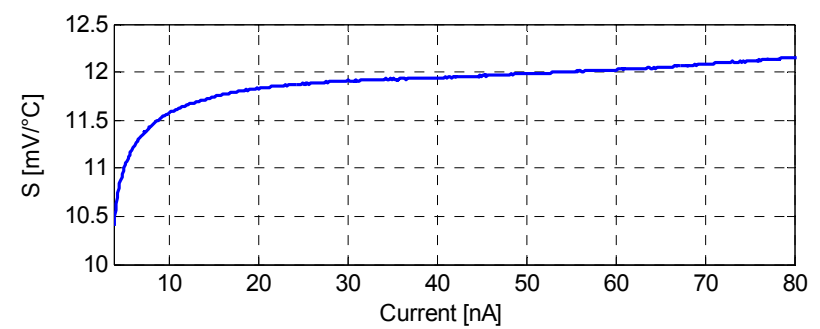

(a)

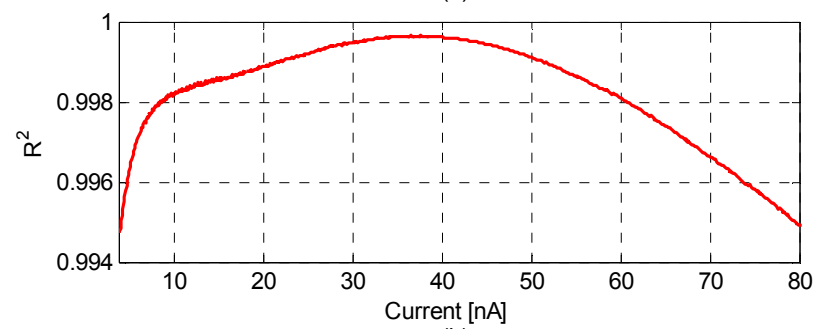

(b)

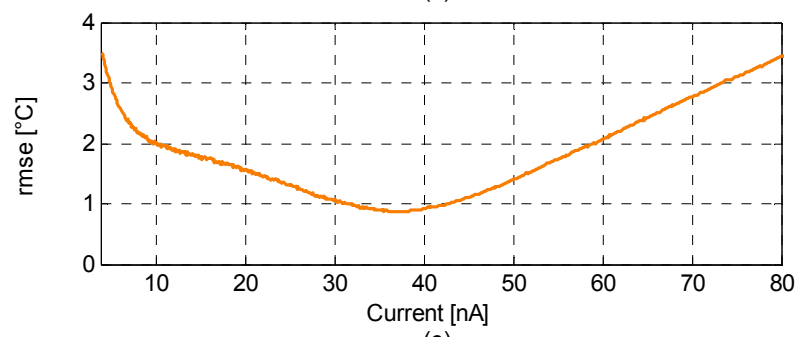

(c)

Figure 3. (a) Sensitivity, $S$; (b) coefficient of determination, $R^{2}$; and (c) root mean square error, $r m s e$, for the whole temperature range of $30-170{ }^{\circ} \mathrm{C}$ for bias currents between $I_{D}=3.7-80 \mathrm{nA}$.

As already mentioned, for actual Si-based integrated active photonic devices, the wavelength shift, due to the temperature change, does not exceed $\sim 100 \mathrm{pm} /{ }^{\circ} \mathrm{C}[14,15]$, and therefore temperature measurements with resolution and accuracy of the order of a few tenths of a degree Celsius match the specifications of any practical control system.

The sensor precision, in term of stability and reproducibility, is a measure of how closely all the measured and calculated data are grouped around the characteristic mean values. In our analysis, the a-Si:H integrated temperature sensor was therefore accurately tested in order to evaluate how consistently it maintains a stable output over time by iteratively repeating three cycles of measurements, from (up to) $30^{\circ} \mathrm{C}$ up to (from) $170{ }^{\circ} \mathrm{C}$, in a long period of time and for five different diodes fabricated with the same process. 
The results are summarized in Figure 4, for $I_{D}=37.3 \mathrm{nA}$, and leaded to a calculated maximum $r m s$ error lower than $\pm 1.7 \%$. Moreover, the coefficient of determination is $R^{2}=0.9993 \pm 3 \times 10^{-4}$ and the corresponding sensitivity is $S=11.89 \mathrm{mV} /{ }^{\circ} \mathrm{C}$ with a standard deviation of $0.08 \mathrm{mV} /{ }^{\circ} \mathrm{C}$.

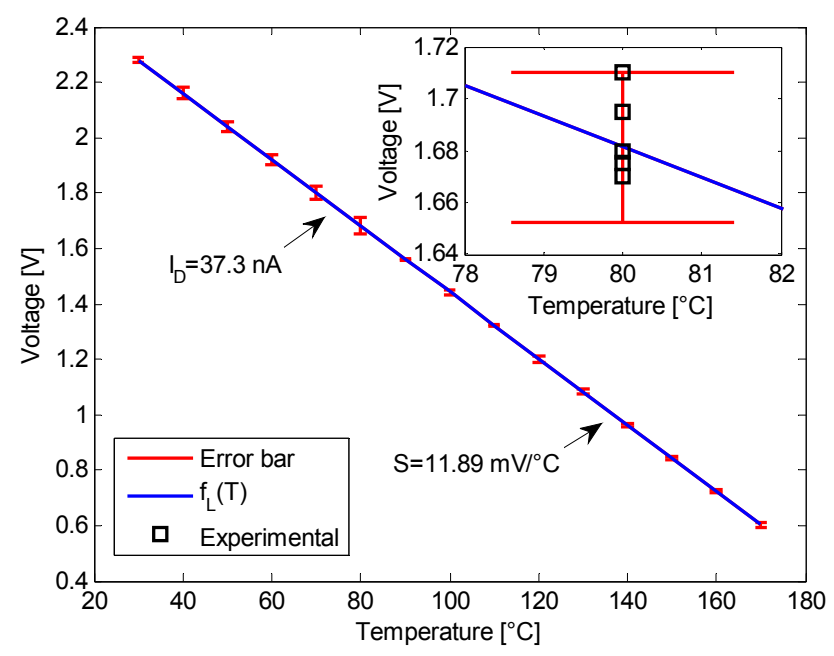

Figure 4. Linear fit and rmse of $V_{D} v s . T$ for five different diodes fabricated with the same technological process and measured in a long period of time. The measurement cycles, from (up to) $30^{\circ} \mathrm{C}$ up to (from) $170^{\circ} \mathrm{C}$, were done in different days. The bias current is $I_{D}=37.3 \mathrm{nA}$ for all five sensors. The inset shows the distribution of $V_{D}$ for the five different diodes at $T=80^{\circ} \mathrm{C}$.

In the inset of Figure 4, the measured voltage drops on the five characterized diodes are shown at the temperature of $80^{\circ} \mathrm{C}$, where the scattering is maximum.

In Figure 5 is shown the power dissipation $\left(P_{D}\right)$ of the a-Si:H temperature sensor, for $I_{D}=37.3 \mathrm{nA}$, in the considered temperature range. The calculated values decrease with temperature with a maximum $P_{D}$ of $\sim 85 \mathrm{nW}$ at $30{ }^{\circ} \mathrm{C}$, low enough to avoid device self-heating.

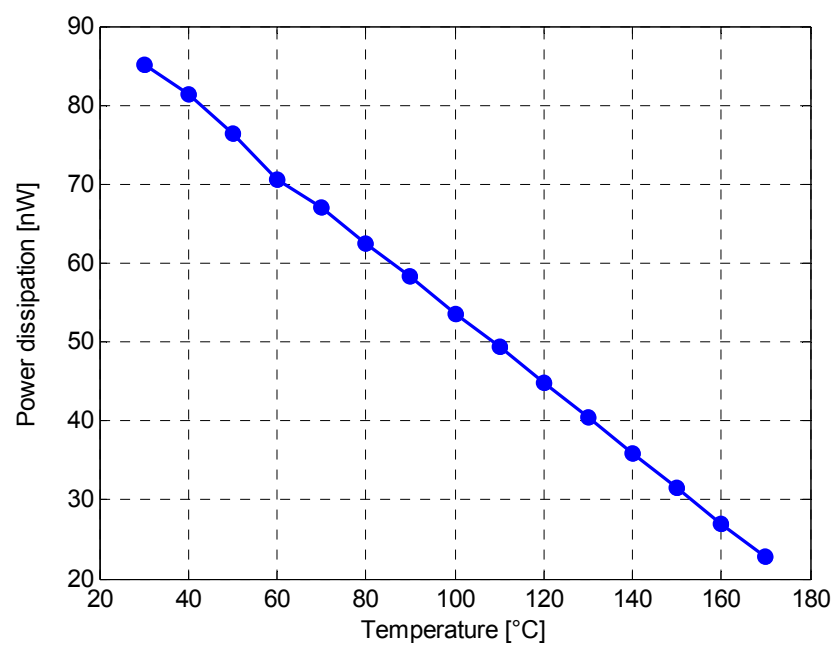

Figure 5. Power dissipation $v$ s. temperature characteristics for $I_{D}=37.3 \mathrm{nA}$.

\section{Conclusions}

A high-performance temperature sensor based on a waveguide integrated a-Si:H p-i-n diode has been designed and characterized. The linear dependence of the voltage drop across the forward-biased diode on temperature, in a range from $30^{\circ} \mathrm{C}$ up to $170^{\circ} \mathrm{C}$, was demonstrated. 
Measurements showed both a high degree of linearity $\left(R^{2}=0.9996\right)$ and a high sensitivity $\left(S=11.9 \mathrm{mV} /{ }^{\circ} \mathrm{C}\right)$ in the biasing current range $\approx 34-40 \mathrm{nA}$ for a device area of $2.25 \times 10^{-4} \mathrm{~cm}^{2}$.

Different cycles of measurements were iterated on five a-Si:H p-i-n diodes showing a long-term stability and good output repeatability.

The proposed a-Si:H temperature sensor, with low power dissipation, high sensitivity, and operating stability can be integrated into photonic integrated circuits (PICs) for sensing applications and inside CMOS compatible photonic active devices for which the temperature variation is a practical issue.

Acknowledgments: The authors are grateful to Pietro Iannì ("Mediterranea” University of Reggio Calabria) for his help with the experimental measurements.

Author Contributions: Sandro Rao conceived the concept and the temperature sensor design for the specific application. Giovanni Pangallo and Sandro Rao focused on the measurement setup, the sensor fabrication and characterization, and on the acquisition of data. Francesco Giuseppe Della Corte supervised the work and together with Sandro Rao contributed to the interpretation and theoretical validation of data. The manuscript was written through the contributions of all authors.

Conflicts of Interest: The authors declare no conflict of interest.

\section{References}

1. Thomson, D.J.; Gardes, F.Y.; Fédéli, J.-M.; Zlatanovic, S.; Hu, Y.; Kuo, B.P.P.; Myslivets, E.; Alic, N.; Radic, S.; Mashanovich, G.Z.; et al. 50-Gb/s Silicon Optical Modulator. IEEE Photonics Technol. Lett. 2012, 24, 234-236. [CrossRef]

2. Lee, Y.H.D.; Thompson, M.O.; Lipson, M. Deposited low temperature silicon GHz modulator. Opt. Express. 2013, 21, 26688-26692. [CrossRef] [PubMed]

3. Ding, J.; Chen, H.; Yang, L.; Zhang, L.; Ji, R.; Tian, Y.; Zhu, W.; Lu, Y.; Zhou, P.; Min, R. Low-voltage, high-extinction-ratio, Mach-Zehnder silicon optical modulator for CMOS-compatible integration. Opt. Express 2012, 20, 3209-3218. [CrossRef] [PubMed]

4. Ding, R.; Baehr-Jones, T.; Pinguet, T.; Li, J.; Harris, N.C.; Streshinsky, M.; He, L.; Novack, A.; Lim, E.; Liow, T.; et al. A silicon platform for high-speed photonics systems. In Proceedings of the Optical Fiber Communication Conference, OSA Technical Digest, Los Angeles, CA, USA, 4-8 March 2012. [CrossRef]

5. Lim, P.H.; Cai, J.; Ishikawa, Y.; Wada, K. Laterally coupled silicon-germanium modulator for passive waveguide systems. Opt. Lett. 2012, 37, 1496-1498. [CrossRef] [PubMed]

6. Rao, S.; Della Corte, F.G.; Summonte, C. Amorphous silicon waveguides grown by PECVD on an Indium Tin Oxide buried contact. Opt. Commun. 2012, 285, 3088-3092. [CrossRef]

7. Casalino, M.; Iodice, M.; Sirleto, L.; Rao, S.; Rendina, I.; Coppola, G. Low dark current silicon-on-insulator waveguide metal-semiconductor-metal photodetector based on internal photoemissions at $1550 \mathrm{~nm}$. J. Appl. Phys. 2013, 114. [CrossRef]

8. Takei, R.; Manako, S.; Omoda, E.; Mori, M.; Sakakibara, Y.; Kamei, T. Highly transpearent submicrometer-sclae amorphous silicon waveguide for backend optical interconnect. In Proceedings of the IEEE Optical Interconnects Conference, San Diego, CA, USA, 4-7 May 2014; pp. 135-136.

9. Lipka, T.; Wahn, L.; Trieu, H.K.; Hilterhaus, L.; Muller, J. Label-free photonic biosensors fabricated with low-loss hydrogenated amorphous silicon resonators. J. Nanophotonics 2013, 7. [CrossRef]

10. Della Corte, F.G.; Rao, S. Use of amorphous silicon for active photonic devices. IEEE Trans. Electron Devices 2013, 60, 1495-1505. [CrossRef]

11. Cocorullo, G.; Della Corte, F.G.; Rendina, I. Temperature dependence of the thermo-optic coefficient in crystalline silicon between room temperature and $550 \mathrm{~K}$ at the wavelength of $1523 \mathrm{~nm}$. Appl. Phys. Lett. 1999, 74, 3338-3340. [CrossRef]

12. Della Corte, F.G.; Montefusco, M.E.; Moretti, L.; Rendina, I.; Cocorullo, G. Temperature dependence analysis of the thermo-optic effect in silicon by single and double oscillator models. J. Appl. Phys. 2000, 88, 7115-7119. [CrossRef]

13. Cocorullo, G.; Della Corte, F.G.; Rendina, I.; Rubino, A.; Terzini, E. Thermo-optical modulation at $\lambda=1.5$ $\mu \mathrm{m}$ in an a-SiC/a-Si/a-SiC planar guided-wave structure. IEEE Photonics Technol. Lett. 1996, 8, 900-902. [CrossRef] 
14. Padmaraju, K.; Bergman, K. Resolving the thermal challenges for silicon microring resonator devices. Nanophotonics 2013, 13, 1-14. [CrossRef]

15. Selvaraja, S.K.; Bogaerts, W.; Van Thourhout, D.; Schaekers, M. Thermal trimming and tuning of hydrogenated amorphous silicon nanophotonic devices. Appl. Phys. Lett. 2010, 97, 071120-1-071120-3. [CrossRef]

16. La Notte, M.; Troia, B.; Muciaccia, T.; Campanella, C.E.; de Leonardis, F.; Passaro, V.M.N. Recent advances in gas and chemical detection by Vernier effect-based photonic sensors. Sensors 2014, 14, 4831-4855. [CrossRef] [PubMed]

17. Lipka, T.; Moldenhauer, L.; Müller, J.; Trieu, H.K. Athermal and wavelength-trimmable photonic filters based on $\mathrm{TiO}_{2}$-cladded amorphous-SOI. Opt. Express 2015, 23, 20075-20088. [CrossRef] [PubMed]

18. Mansoor, M.; Haneef, I.; Akhtar, S.; de Luca, A.; Udrea, F. Silicon diode temperature sensors-A review of applications. Sens. Actuators A Phys. 2015, 232, 63-74. [CrossRef]

19. Zhang, N.; Lin, C.-M.; Senesky, D.G.; Pisano, A.P. Temperature sensor based on $4 \mathrm{H}$-silicon carbide pn diode operational from $20^{\circ} \mathrm{C}$ to $600^{\circ} \mathrm{C}$. Appl. Phys. Lett. 2014, 104. [CrossRef]

20. Udrea, F.; Santra, S.; Gardner, J.W. CMOS temperature sensors-Concepts, state-of-the-art and prospects. In Proceedings of the CAS 2008 International Semiconductor Conference, Sinaia, Romania, 13-15 October 2008; pp. 31-40.

21. De Cesare, G.; Nascetti, A.; Caputo, D. Amorphous Silicon p-i-n Structure Acting as Light and Temperature Sensor. Sensors 2015, 15, 12260-12272. [CrossRef] [PubMed]

22. Rao, S.; Coppola, G.; Gioffrè, M.A.; Della Corte, F.G. A 2.5 ns switching time Mach-Zehnder modulator in as-deposited a-Si:H. Opt. Express 2012, 20, 9351-9356. [CrossRef] [PubMed]

23. Della Corte, F.G.; Rao, S.; Coppola, G.; Summonte, C. Electro-optical modulation at $1550 \mathrm{~nm}$ in an as-deposited hydrogenated amorphous silicon p-i-n waveguiding device. Opt. Express 2011, 19, 2941-2951. [CrossRef] [PubMed]

24. Santra, S.; Guha, P.K.; Ali, S.Z.; Haneef, I.; Udrea, F. Silicon on insulator diode temperature sensor-A detailed analysis for ultra-high temperature operation. IEEE Sens. J. 2010, 10, 997-1003. [CrossRef]

25. Rao, S.; Della Corte, F.G.; Pangallo, G. 4H-SiC p-i-n diode as Highly Linear Temperature Sensor. IEEE Trans. Electron Devices 2015, 63, 414-418. [CrossRef]

26. Nagelkerke, N.J.D. A Note on a General Definition of the Coefficient of Determination. Biometrika 1991, 78, 691-692. [CrossRef]

27. Meijer, G.C.M.; Verhoeff, J.B. An integrated bandgap reference. IEEE J. Solid-State Circuits 1976, 11, $403-406$. [CrossRef]

28. Banerjee, A.; Park, Y.; Clarke, F.; Song, H.; Yang, S.; Kramer, G.; Kim, K.; Mukherjee, B. Wavelength-division-multiplexed passive optical network (WDM-PON) technologies for broadband access: A review. J. Opt. Netw. 2005, 4, 737-758. [CrossRef] 